\title{
Approaches for Modelling the Residual Service Life of Marine Concrete Structures
}

\author{
Amir Rahimi, ${ }^{1}$ Christoph Gehlen, ${ }^{2}$ Thorsten Reschke, ${ }^{1}$ and Andreas Westendarp ${ }^{1}$ \\ ${ }^{1}$ Federal Waterways Engineering and Research Institute (BAW), 76187 Karlsruhe, Germany \\ ${ }^{2}$ Centre for Building Materials (CBM), Technische Universität München, 81245 Munich, Germany
}

Correspondence should be addressed to Amir Rahimi; amir.rahimi@baw.de

Received 6 September 2013; Accepted 2 December 2013; Published 12 January 2014

Academic Editor: Sebastian Feliu

Copyright (c) 2014 Amir Rahimi et al. This is an open access article distributed under the Creative Commons Attribution License, which permits unrestricted use, distribution, and reproduction in any medium, provided the original work is properly cited.

This paper deals with the service life design of existing reinforced concrete structures in a marine environment. The general procedure of condition assessment for estimating the residual service life of structures before a repair measure is illustrated. For assessment of the residual service life of structures which have undergone a repair measure a simplified mathematical model of chloride diffusion in a 2-layer system is presented. Preliminary probabilistic calculations demonstrate the effect of various conditions on the residual service life. First studies of the chloride diffusion in a 2-layer system have been conducted using the finite element method. Results of a long-term exposure test are presented to illustrate the performance of two different repair materials. The distribution of residual chlorides after application of a repair material is being studied in laboratory investigations. The residual chlorides migrate from the concrete layer into the new layer immediately after the repair material has been applied to the concrete member. The content and gradient of residual chlorides, along with the thickness and the chloride ingress resistance of both the remaining and the new layer of cover, will determine the residual service life of the repaired structures.

\section{Introduction}

Concrete structures in a marine environment such as locks, dams and bridges are affected by a wide range of degradation phenomena. Chloride-induced corrosion is the decisive aspect in the durability of such structures. Reinforcement corrosion is initiated when a critical chloride content is reached at the surface of the rebars. Chloride contents higher than the critical value can cause disruption of the protective passive layer, leading to corrosion of the rebars. The time required to initiate corrosion depends, apart from some environmental factors, on the properties of the concrete, in particular on its resistance to chloride diffusion.

The following period, the propagation period, refers to the evolution of different forms of deterioration after corrosion has been initiated (cracking, spalling, loss of bond between rebars, and concrete and reduction in the rebar cross-section). Although the service life of structures is the sum of these two periods, in most cases the initiation period defines the service life because the propagation period may be very short.
A traditional and feasible repair method consists of removing the chloride-contaminated concrete layer and replacing the removed volume by cement-based repair mortars or concretes. The aim of this measure is either to maintain the existing passivity of the reinforcement over the remaining service life or to restore the passivity of the reinforcement.

In recent years probabilistic service life design models have been developed for new structures, using time-dependent models to describe the chloride ingress into concrete. Besides empirical models, Fick's second law of diffusion is also applied with some modifications as diffusion is the most active mechanism in chloride transport in concrete. For repaired structures, the transport model first has to be adapted to a two-layer model which not only considers the layer of repair material and the remaining concrete layer but also considers their interface. Where chloride ions are present in the remaining concrete layer, the possibility of diffusion into the repair phase as well as further diffusion towards the inside of the structure both have to be considered. 


\section{Service Life Design of (New) Concrete Structures for Chloride-Induced Corrosion}

In order to satisfy the requirements for the durability of concrete structures the deemed-to-satisfy provisions, which are based on practical experience, have to be complied with. These rules are given in current standards and guidelines. As a contrast to the prescriptive methodology of standards, performance-based probabilistic design models are being developed. The "fib model code for service life design" [1] presents a full probabilistic concept for the service life design of uncracked concrete structures for the case of chlorideinduced corrosion. The concept is based on the following:

(i) definition of limit states,

(ii) models which are able to describe the time-dependent transport and deterioration mechanisms,

(iii) statistical definition of actions,

(iv) measurement and statistical quantification of building component resistances,

(v) assumed permissible failure probabilities.

The limit state is determined by the initiation of reinforcement corrosion and reached when a critical chloride content is exceeded at the rebar surface, disrupting the passive layer protecting the rebar. At the end of the initiation period, no corrosion-induced deterioration will have yet occurred in the structure. High corrosion rates are observed in marine environments in general so that the deterioration period is comparatively short. Moreover, there is yet no commonly used model to describe the mechanism of reinforcement corrosion and its effect on structures. Therefore the deterioration period is disregarded in this concept and the service life is considered as the initiation period.

To assess the initiation period, a mathematical model, (1), is used to estimate the time- and depth-dependent chloride concentration, $C(x, t)$, in the concrete, based on the error function solution of Fick's second law of diffusion in the onedimensional form. This diffusion-controlled assessment of chloride ingress is only a simplification since other transport mechanisms are involved in the chloride ingression into concrete, in particular capillary absorption and permeation. However, in structures with concrete cover depths greater than approximately $30 \mathrm{~mm}$, diffusion becomes the most effective and important mechanism with regard to the initiation of corrosion in concrete structures. Consider

$$
\begin{aligned}
C(x, t)= & C_{0}+\left(C_{S, \Delta x}-C_{0}\right) \\
& \cdot\left[1-\operatorname{erf} \frac{x-\Delta x}{2 \cdot \sqrt{D_{\mathrm{app}, C}(t) \cdot t}}\right],
\end{aligned}
$$

where $C_{0}$ is the initial chloride content (wt.-\%/c), $C_{s, \Delta x}$ is the chloride content at the depth $\Delta x$ and a certain point of time in relation to the environment (wt.-\%/c), $\Delta x$ is the depth of the convection zone (concrete layer up to which the process of chloride penetration differs from Fick's 2nd law of diffusion) (mm), $x$ is the depth with a corresponding content of chlorides $C(x, t)(\mathrm{mm}), t$ is the time (years), and $D_{\text {app,C }}(t)$ is the apparent chloride diffusion coefficient $\left(\mathrm{m}^{2} / \mathrm{s}\right)$.

It can be concluded that the rate at which chlorides penetrate concrete is governed by the diffusivity of the concrete (material) and concentration of the chloride load (environment).

Although $C_{s, \Delta x}$ is theoretically a time-dependent variable, it will be considered as time-independent for simplicity.

The apparent chloride diffusion coefficient, $D_{\text {app,C }}(t)$ $\left(\mathrm{m}^{2} / \mathrm{s}\right)$, is regarded to be time dependent and is to be determined by means of (2)

$$
\begin{aligned}
D_{\mathrm{app}, C}(t)=\exp ( & \left.b_{e}\left(\frac{1}{T_{\text {ref }}}-\frac{1}{T_{\text {real }}}\right)\right) \\
& \cdot D_{\mathrm{RCM}, 0} \cdot k_{t} \cdot\left(\frac{t_{0}}{t}\right)^{\alpha},
\end{aligned}
$$

where $b_{e}$ is the temperature coefficient $(\mathrm{K}), T_{\text {ref }}$ is the reference temperature (for laboratory tests) $(\mathrm{K}), T_{\text {real }}$ is the temperature of the structural element or the ambient air $(\mathrm{K}), D_{\mathrm{RCM}, 0}$ is the chloride migration coefficient $\left(\mathrm{m}^{2} / \mathrm{s}\right), k_{t}$ is the transfer parameter $(=1)(-), t_{0}$ is the reference point of time $(s)$, and $\alpha$ is the ageing exponent (-).

Due to the intermittent wetting and drying of the nearsurface layer (approximately within the first $20 \mathrm{~mm}$ ), particularly in tidal and splash zones, the transport mechanisms in this layer greatly differ from Fick's law of diffusion. Modelling is therefore conducted with a substitute surface chloride concentration, $C_{s, \Delta x}$, disregarding the data in the convection zone, $\Delta x$.

$D_{\mathrm{RCM}, 0}$ and the ageing exponent, $\alpha$, are the governing parameters for the description of the material properties. While $D_{\mathrm{RCM}, 0}$ is simply determined by rapid chloride migration (RCM) test methods $[2,3]$, the ageing exponent, which operates the decrease of $D_{\text {app,C }}(t)$ over time, is both material and exposure dependent and cannot be determined by laboratory tests alone. To determine the ageing factor, the long-term behavior of $D_{\text {app,C }}(t)$ of existing structures has to be considered by processing the chloride profiles over time. Gehlen [4] quantified the statistical distribution of the ageing exponent of concretes consisting of three different types of cement, considering both the chloride profiling data for several existing structures and the RCM test results at the reference time (28 days), $D_{\mathrm{RCM}, 0}$.

The limit state equation is obtained by comparing the calculated chloride content in the concrete cover (position of rebars) at the time $t, C(x=a, t)$, and the critical chloride content, $C_{\text {crit }}$ :

$$
g\left(C_{\text {crit }}, C(x=a, t)\right)=C_{\text {crit }}-C(x=a, t)<0 .
$$

Although only the free chloride ions that have dissolved in the pore solution of the concrete result in depassivation of the reinforcement, the overall chloride content is included in the model as it is difficult to determine the free chloride content in the concrete. The critical chloride content, $C_{\text {crit }}$, is to be quantified statistically and inserted into the model. In [1], some stochastic values for the input parameters are 


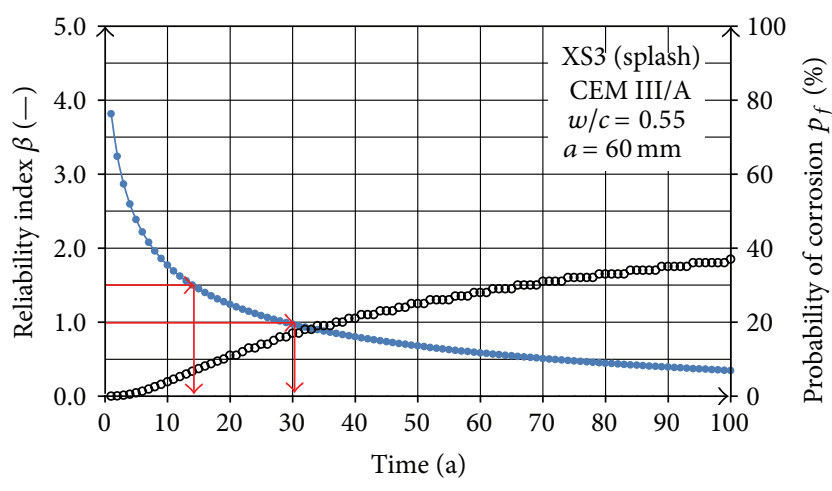

(a)

\begin{tabular}{c|c} 
Parameter & Distribution and values \\
\hline$D_{\mathrm{RCM}}\left(\cdot 10^{-12} \mathrm{~m}^{2} / \mathrm{s}\right)$ & $\mathrm{ND}(5.0 / 1.0)$ \\
\hline$t_{0}(s)$ & Constant $2,419,20(28 \mathrm{~d})$ \\
\hline Ageing factor $\alpha(-)$ & $\beta D(0.40 / 0.18 / 0 / 1)$ \\
\hline$T_{\text {ref }}(\mathrm{K})$ & Constant 273 \\
\hline$T_{\text {real }}(\mathrm{K})$ & $\mathrm{ND}(283 / 7)$ \\
\hline$b_{e}(\mathrm{~K})$ & $\mathrm{ND}(4800 / 700)$ \\
\hline$a(\mathrm{~mm})$ & $\mathrm{ND}(60 / 6)$ \\
\hline$C_{\Delta x, s}(\mathrm{wt} .-\% / \mathrm{c})$ & $\mathrm{LND}(3.0 / 1.4)$ \\
\hline$\Delta x(\mathrm{~mm})$ & $\beta D(8.9 / 5.6 / 0 / 50)$ \\
\hline$k_{t}(-)$ & $\mathrm{Constant} 1$ \\
\hline$C_{\text {crit }}(\mathrm{wt} .-\% / c)$ & $\beta D(0.60 / 0.15 / 0.2 / 2)$
\end{tabular}

(b)

FIGURE 1: Development of reliability index and probability of corrosion over time of a marine structural element (a) with the input parameters (b).

recommended (e.g., Figure 1(b)). A reliability analysis is performed using the limit state equation (3) and by specifying a minimum reliability index, $\beta$. There is a correlation between the reliability index, $\beta$, and the probability of failure, $p_{f}$. EN $1990[5]$ and ISO $2394[6,7]$ give recommendations for the reliability index for serviceability limit states depending on the expenditure required to reduce risk from $\beta=0$ to $\beta=2.3$.

The diagram in Figure 1 is an example of a reliability analysis used to predict the service life of a structural element (formerly common concrete composition for marine structural elements: CEM III/A (GGBS cement), $w / c=0.55$, $a=60 \mathrm{~mm})$. A target reliability index of $\beta=1.5\left(p_{f}=6.7 \%\right)$ is expected after a 14-year period of exposure to severe tidal / splash conditions. A lower target reliability index of $\beta=1.0$ $\left(p_{f}=16 \%\right)$ is expected at an age of 30 years. The input parameters are illustrated in Figure 1(b).

This model is applied during the design stage of new structures by inserting input parameters of the material properties, of the cover depth and of actions into (3).

The model can also be used to assess the durability of existing structures and to predict their residual service life by determining the current material properties and the actual actions statistically and inserting them into the model (see Section 3). However, some modifications are required in order to model the residual service life design after a repair measure, for example, application of repair mortars, since the chloride ingress model first has to be adapted to a 2-layer model considering both the repair and remaining concrete layers and their interface.

\section{Condition Assessment and Appraisal of the Residual Service Life before Carrying out a Repair Measure}

The majority of activities in the construction sector concern existing structures. Most of these structures have not been designed with their service life in mind; in many cases, the composition of the concrete and the details of the design are unknown. The first step towards estimating their durability is to determine what condition they are in. Visual inspection is not helpful when considering the chloride-induced corrosion of reinforcement as the initiation of corrosion, which is decisive for the service life model considered here, does not cause any visible damage to the structure. Structures with visible corrosion damage have reached the end of their service life (initiation period). Further studies of the structure can provide information on the extent, intensity, and development of the corrosion process and subsequent effects.

The flow chart in Figure 2, from fib bulletin 59 [8], shows a procedure of estimating the service life of existing structures. The procedure involves considering members which have not undergone repairs so that the service life model presented above for design of new structures can be applied.

The development of the chloride content in the concrete cover must be determined by appropriate sampling, as must the thickness of the concrete cover if unknown. The concrete composition (type and content of binder, $w / b$-ratio) must be determined conservatively by sampling and laboratory tests if no information on it is available. A service life prediction must first be drawn up taking the concrete composition that is used or estimated and the existing concrete cover into account and the development of the reliability index, $\beta$, over time must be determined.

The chloride profiles enable condition assessment, which is associated with a degree of uncertainty, to be improved. However, as there is also a certain level of uncertainty in the inspection data, the prediction is updated by means of a probabilistic format using Bayes theorem [9] in which the uncertain expected values (a priori model) are supported by real data determined on the structure and thus converted into a posteriori model. Bayes theorem enables previously calculated levels of reliability and probabilities of failure to be updated.

After the condition assessment has been updated, the residual service life can be determined. Depending on the level of reliability achieved it will either be necessary to draw up plans for a later inspection or undertake measures such as further investigations, repairs, or even a reduction in the expected safety level. 


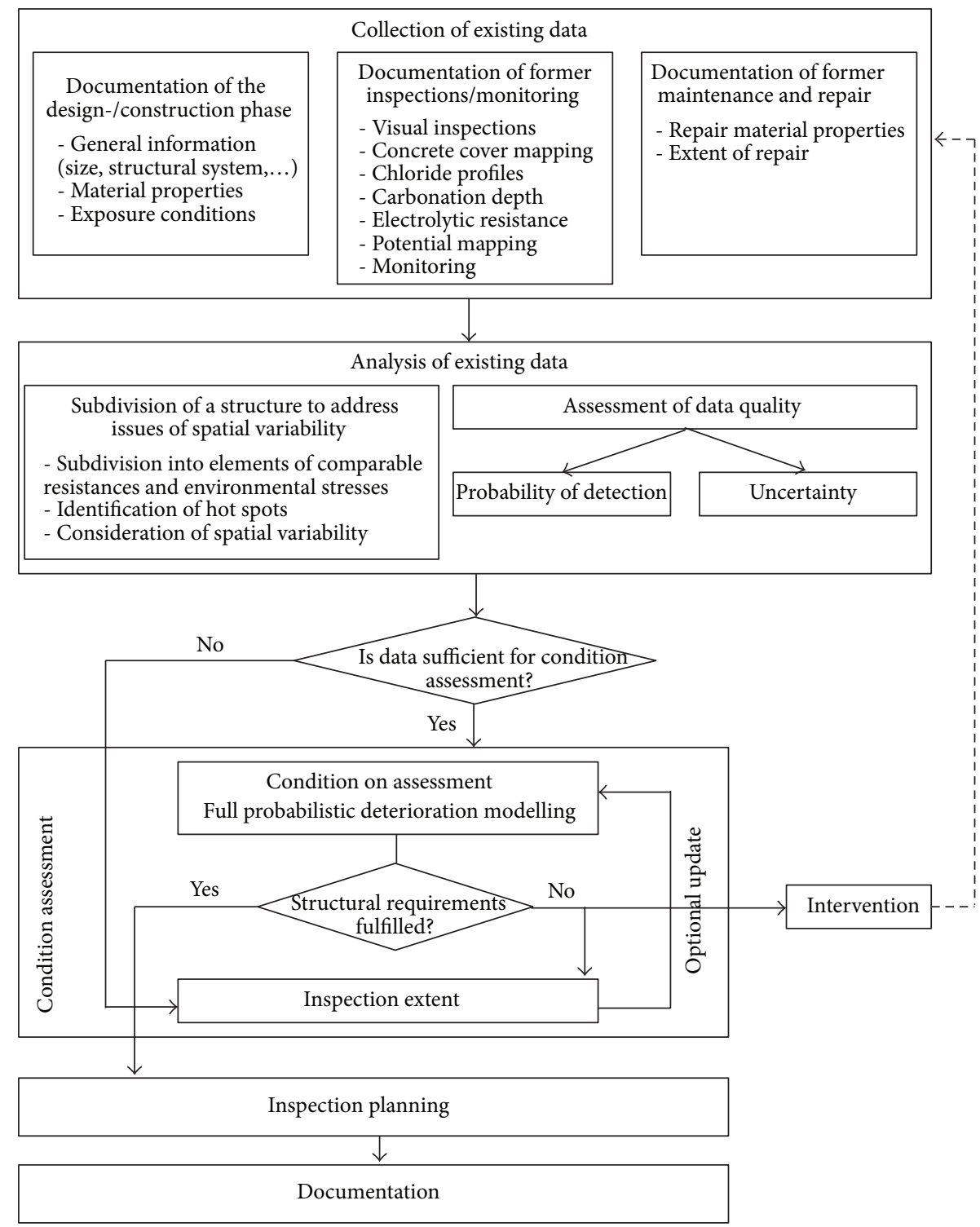

Action

Decision

FIGURE 2: Flow chart for the condition assessment of existing structures (before repair) [8].

Depending on the information that is available for the structure, there may be a lower or greater number of uncertainties in the input parameters of the model than in the case of the service life design for new structures (a different statistical quantification). For example, the actual concrete cover can be determined in detail, quantified statistically, and used in the model.

In Figure 3(b), the updated reliability index development of a structural element is illustrated using chloride profiles taken after 28 years' exposure on the German Baltic Sea coast (see Figure 3(a)). The updated $\beta$-t-run exhibits at the inspection time a higher value than of the a priori design, but it takes a more regressive course. For assumed target reliability index of for instance 1.5 the service life will be expected for 40 years, which is much more than the predicted one by the a priori design (14 years). Drawing up a next inspection (e.g., 10 years later) would be a feasible provision in this case.

\section{Estimation of the Residual Service Life after Repair}

The model for service life design presented above requires modification before it can be applied to repaired members as chloride transport in this case takes place in two layers consisting of different materials. 


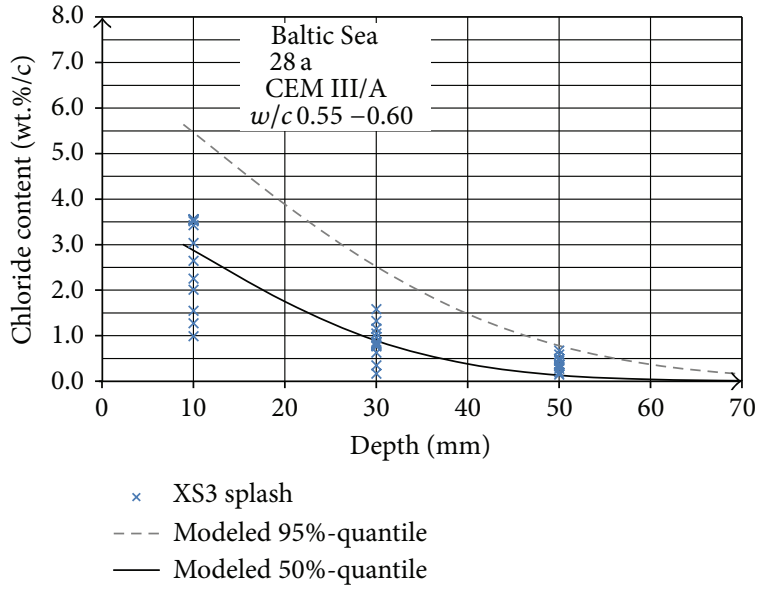

(a)

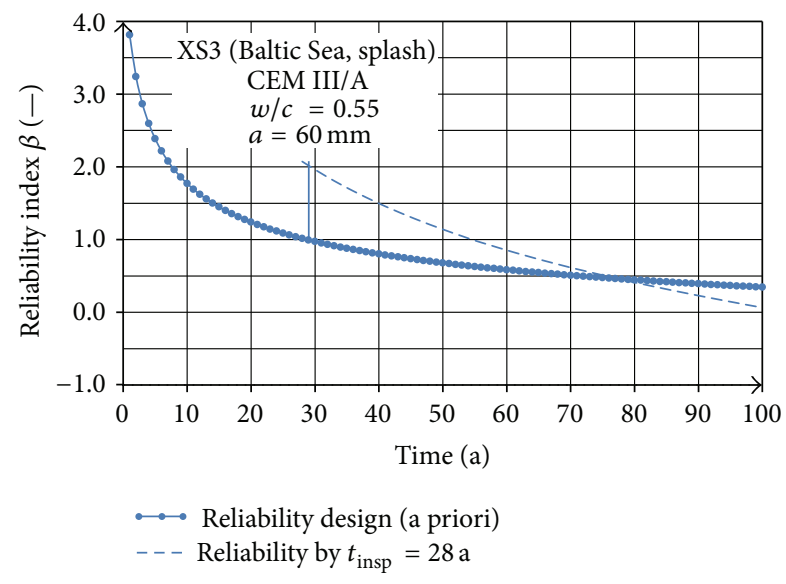

(b)

FIgURE 3: (a): Measured and calculated chloride values of several elements of a marine structure after 28 years' exposure, (b): assessment of the residual service life of the same structure by updating the a priori design by means of the measured chloride profiles.

4.1. Mathematical Description of Chloride Penetration in a 2Layer System. Three different cases need to be considered when carrying out repairs which involve replacing sections of the concrete with a repair mortar or concrete.

Case 1. The concrete cover is removed entirely and replaced with a repair material. The remaining layer of concrete behind the reinforcement is not affected by chloride ions.

In this case, the design of the service life of a structure with regard to chloride-induced corrosion of the reinforcement is based on a common 1-layer system. The design model described in Section 2 can be used to determine the chloride penetration into the concrete and to calculate the residual service life of a structural element, stating the characteristics of the repair material.

Case 2. The concrete cover is only partially removed and replaced with a repair material. The remaining layer of concrete in the cover and behind the reinforcement is not affected by chloride ions; see Figure 4(a).

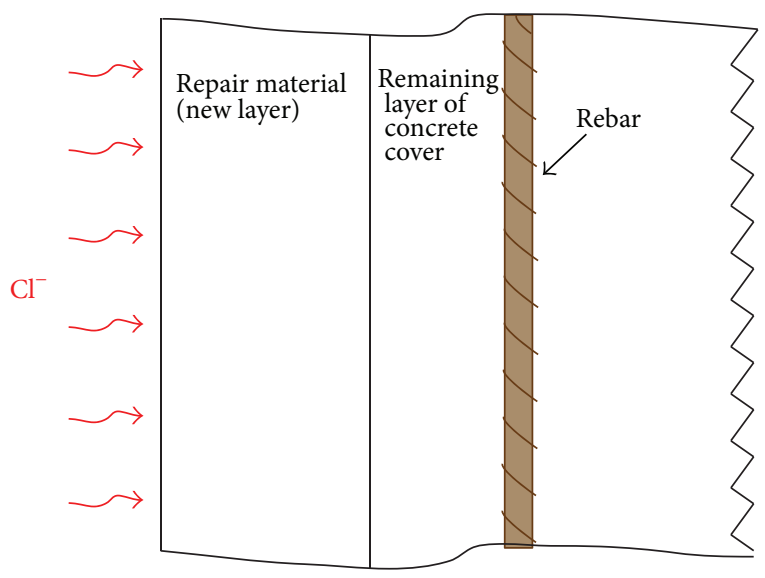

(a)

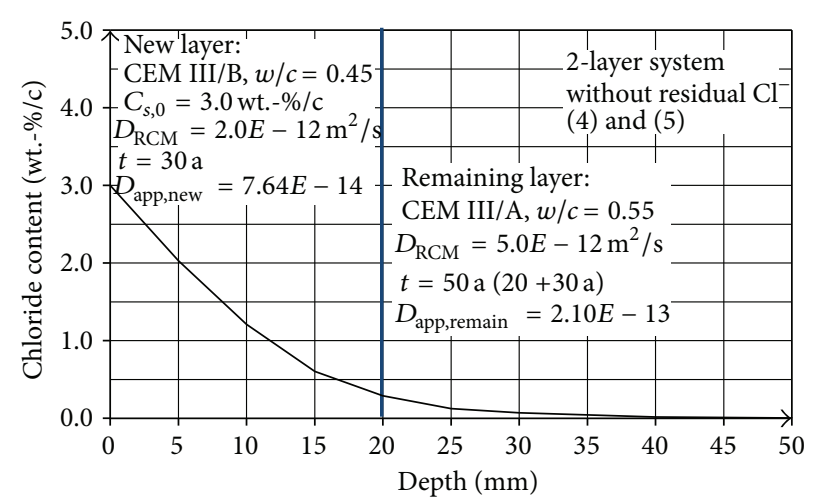

(b)

FIGURE 4: Chloride penetration in a repaired concrete element: 2layer system.

In this case, the concrete cover comprises two layers with different material characteristics: a new layer "new" and the remaining layer "remain". The initiation period depends on the chloride penetration behavior of the two layers. The mathematical modelling of the penetration behavior of chloride ions in such a 2-layer system can be determined as follows using the diffusion equations developed by Carslaw and Jeager $[10,11]$ :

$$
\begin{aligned}
C_{\text {new }}(x, t)=C_{s, 0} \sum_{n=0}^{\infty} \alpha^{n}\{ & \operatorname{erfc} \frac{(2 n+1) \cdot a_{\text {new }}+x}{2 \sqrt{D_{\text {app,new }}(t) \cdot t}} \\
& \left.-\alpha \cdot \operatorname{erfc} \frac{(2 n+1) \cdot a_{\text {new }}-x}{2 \sqrt{D_{\text {app,new }} \cdot t}}\right\},
\end{aligned}
$$

$$
\begin{aligned}
C_{\text {remain }}(x, t)= & \frac{2 k \cdot C_{s, 0}}{k+1} \\
& \cdot \sum_{n=0}^{\infty} \alpha^{n} \cdot \operatorname{erfc} \frac{(2 n+1) \cdot a_{\text {new }}+k \cdot x}{2 \sqrt{D_{\text {app,new }} \cdot t}}
\end{aligned}
$$




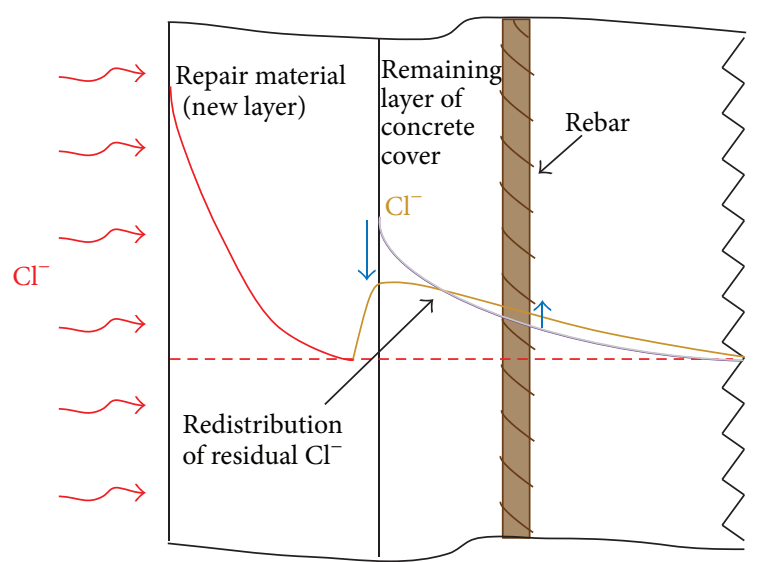

FIGURE 5: Chloride ingress and redistribution in a repaired concrete element (2-layer system) with residual chloride ions.

with

$$
k=\sqrt{\frac{D_{\text {app,new }}}{D_{\text {app,remain }}}}, \quad \alpha=\frac{1-k}{1+k},
$$

where $\operatorname{erfc}(x)$ is the complementary error function (1 $\operatorname{erf}(x))$. The chloride ion concentration in the layer of repair material, $\left(C_{\text {new }}(x, t)\right)$ is described using (4) and that of the remaining layer of concrete, $\left(C_{\text {remain }}(x, t)\right)$, using $(5)$. The boundary conditions for the new layer are a constant surface chloride concentration, $\left(C_{s, 0}=\right.$ const. $)$, and an equilibrium concentration at the interface, $\left(C_{\text {new }}(x=0, t)=C_{\text {remain }}(x=\right.$ $0, t))$. Figure 4(b) shows a typical graph for the development of the chloride concentration in a 2-layer system, in this special case after 30 years' exposure.

Any interfacial resistance at the repair material/concrete layer is disregarded here. The interfacial resistance can be caused by the incoherence of the pore structure of the two materials (pore blocking) and by the large proportion of impermeable aggregates in the remaining layer. In this case, the boundary condition of the equilibrium concentration at the interface is not satisfied in the above approach.

Case 3. The concrete cover is only partially removed and replaced with repair material. The remaining layer of concrete contains (residual) chlorides. The same situation occurs when the contaminated concrete cover is left in place and topped with a layer of repair material.

In this case, the result is also a 2-layer system except that, by contrast with Case 2, the residual chlorides are redistributed in the new layer and within the structural element in addition to chloride ingress; see Figure 5. The redistribution of the residual chlorides cannot be described mathematically by the error function of Fick's second law of diffusion as the required boundary condition of a constant concentration at the phase boundary, $\partial C_{s} / \partial t=0$, no longer applies. The diffusion process can be described by means of
(8) if the concentration at the phase boundary varies at a known rate of concentration change (see (7)) [11]. Consider

$$
\begin{gathered}
C_{s}=C_{0}-k t, \\
C(x, t)=C_{0} \operatorname{erfc} \frac{x}{2 \sqrt{D t}}-4 k t i^{2} \operatorname{erfc} \frac{x}{2 \sqrt{D t}}
\end{gathered}
$$

where $i$ is the imaginary unit and $k$ is the rate of concentration change per unit time. In order to model the redistribution of the residual chlorides, the rate of concentration change, $k$, must therefore be determined first. A distinct mobilization of the residual chlorides, triggered by the moisture in the new layer, is expected to occur directly after application of the repair material. The residual chlorides can either migrate further into the remaining concrete layer owing to capillary suction or can be washed out and transported into the new layer. Depending on the moisture content of the remaining concrete layer, transport of the chloride ions into the new layer by diffusion is also possible. This important issue is currently being investigated in ongoing laboratory investigations being carried out by the authors (see Section 4.5). The results of the investigations clearly show that significant amounts of residual chlorides migrate into the layer of repair material.

Studies by Martin [12] of repaired concrete beams contaminated by chlorides have also shown that there is a substantial transport of residual chlorides into the new layer. The most significant transport of the residual chlorides into the layer of repair material occurred shortly after the layer had been applied (first measurement 2 years after application). The later diffusion-controlled transport of chlorides (after 6 years) took place at a much slower rate. The studies also showed diffusion of the residual chlorides within the beams [12].

A mathematical model for describing chloride penetration in 2-layer systems with residual chlorides does not yet exist. Ongoing studies dealing with the description and modelling of the various mechanisms of chloride transport in 2-layer systems are presented in Section 4.5.

4.2. An Approximate Calculation of Residual Service Life. One of the most important preconditions for predicting the service life of a structure is the availability of mathematical models to describe the relevant transport and/or deterioration mechanisms (see Section 2). However, the models needed to calculate the residual service life of repaired structural elements, as described in Section 3, do not yet exist. The main problem is the presence of residual chlorides in the remaining layer of concrete. Nonetheless, the residual service life can be approximated initially by means of the simplified approach described below (see also [13]).

The mathematical model used is the approach proposed by Carslaw and Jeager (see (4) and (5)). The residual chloride content at the surface of the reinforcement, $\left(C_{r}\right)$, is determined/specified. The limit state is taken to be the point at which a chloride content defined as the difference between the critical chloride content $\left(C_{\text {crit }}\right)$ and the residual chloride content $\left(C_{c r i t}-C_{r}\right)$ is reached at the surface of the reinforcement due to the ingress of external chloride ions. The 


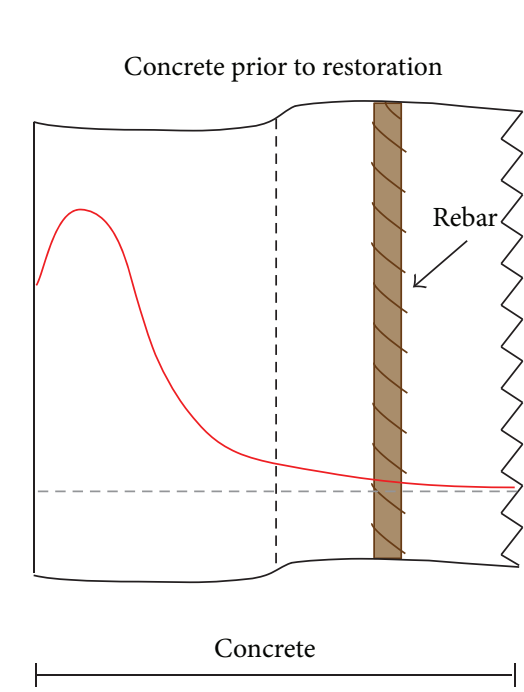

(a)

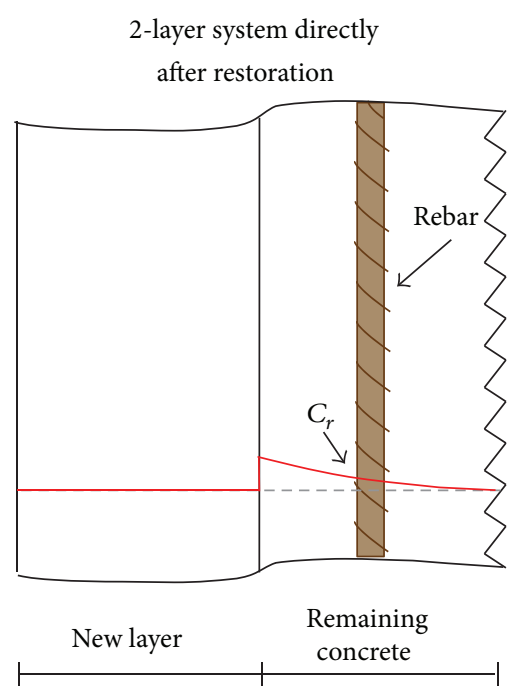

(b)

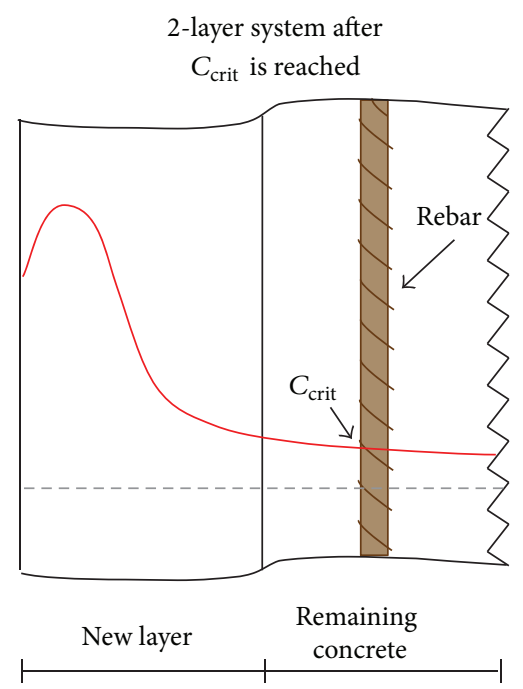

(c)

FIGURE 6: Schematic representation of the chloride profiles in a repaired concrete structural element.

gradient of the residual chloride profile and its redistribution are not taken into account. The procedure described above is illustrated in Figure 6.

The limit state equation for the reliability analysis is, by analogy to the 1-layer system (see, (3)), as follows:

$$
\begin{aligned}
& g\left(C_{\text {crit }}, C_{r}, C_{\text {remain }}\left(a_{\text {remain }}, a_{\text {new }}, t\right)\right) \\
& \quad=\left(C_{\text {crit }}-C_{r}\right)-C_{\text {remain }}\left(a_{\text {remain }}, a_{\text {new }}, t\right)<0 .
\end{aligned}
$$

The results of the reliability analyses performed as shown above for a typical 2-layer system comprising a $40 \mathrm{~mm}$ thick layer of repair material made of CEM III/B concrete (GGBS cement) and a $20 \mathrm{~mm}$ thick layer of remaining concrete made of CEM I (OPC) concrete are shown in Figure 7. The residual chloride content at the surface of the reinforcement, $C_{r}$, was varied, being taken to be $0,0.1$, or $0.2 \mathrm{wt} .-\% / \mathrm{c}$. By analogy to the 1-layer system [1], a beta distribution with a mean value of $0.6 \mathrm{wt} .-\% / \mathrm{c}$ was assumed for the critical chloride content. The variation of the residual chloride content results in different service lives of approximately 55,45 , and 35 years, for a target reliability index of 1.5 .

By way of comparison, a calculation was performed without taking into account the layer of remaining concrete. In this 1-layer system, the initiation period was calculated on the basis of the point at which a critical chloride content of $0.6 \mathrm{wt} .-\% / \mathrm{c}$ was reached at the interface with the layer of remaining concrete $(x=40 \mathrm{~mm})$. In this case, a service life of around 12 years was determined.

The results of the analyses indicate that the residual chloride content at the surface of the reinforcement is of great importance for the residual service life of the structural element. The extent to which disregarding the gradient of the residual chlorides and their redistribution affects the results has not yet been investigated. The question of whether the assumptions result in a conservative calculation of the residual service life or the opposite also remains unanswered.

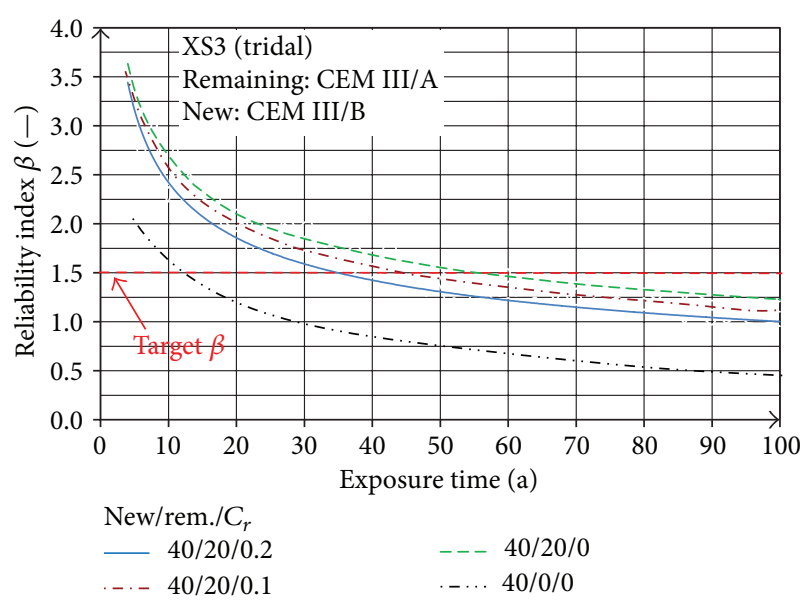

(a)

\begin{tabular}{c|c|c}
\multirow{2}{*}{ Input parameters: } \\
$D_{\mathrm{RCM}}\left(\cdot 10^{-12} \mathrm{~m}^{2} / \mathrm{s}\right)$ & Remaining concrete & Repair material \\
\cline { 2 - 3 } & $\begin{array}{c}\beta D \\
\text { Ageing factor } \alpha(-)\end{array}$ & $\begin{array}{c}\beta D \\
(0.40 / 0.18 / 0 / 1)\end{array}$ \\
\hline$C_{s}(\mathrm{wt} .-\% / \mathrm{c})$ & - & $\mathrm{LND}(3 / 1.4)$ \\
\hline$T(\mathrm{~K})$ & \multicolumn{2}{|c}{$\mathrm{ND}(283 / 7)$}
\end{tabular}

(b)

FIGURE 7: Estimated corrosion initiation time after application of a repair material.

The reliability analyses were performed using the STRUREL program [14].

In the following section, the redistribution of the residual chlorides is investigated numerically using the finite element method. 


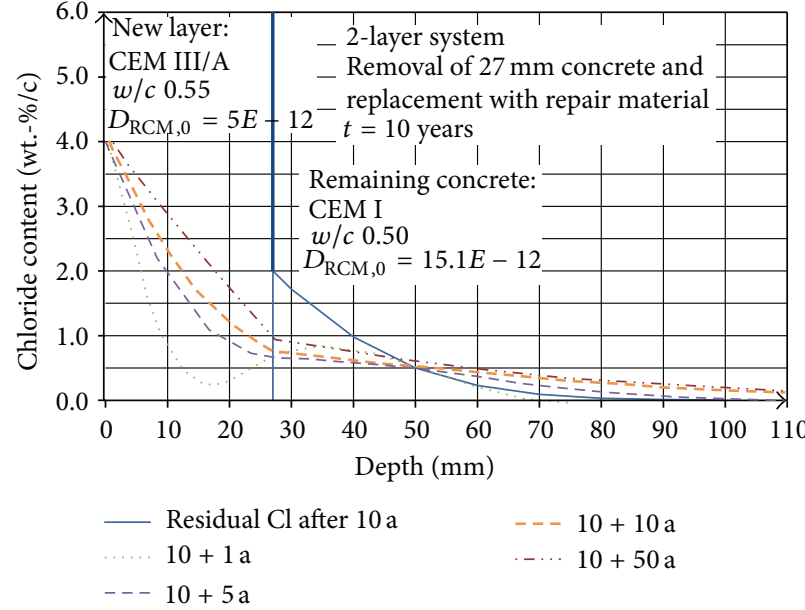

(a)

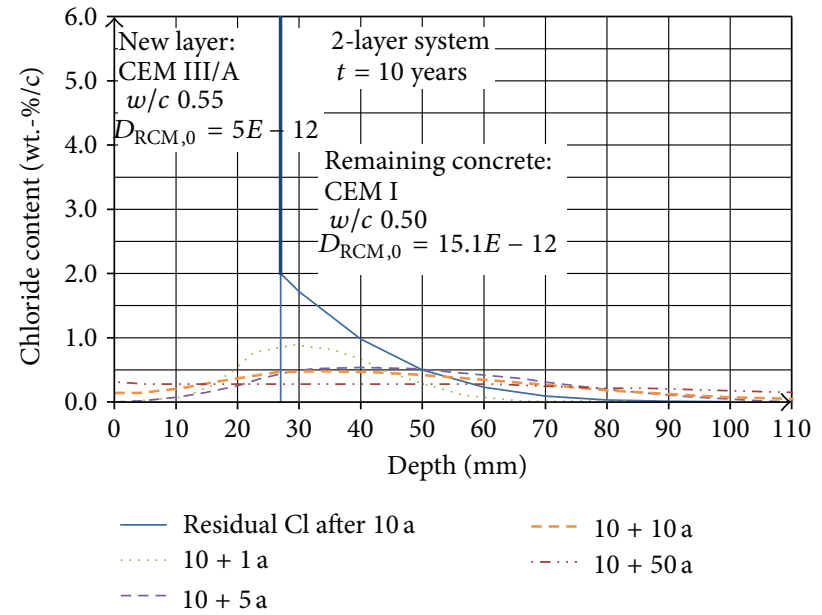

(b)

FIGURE 8: FE simulation of chloride ingress and redistribution in a 2-layer system (a): both residual and external chloride ions are present and (b): redistribution of residual chloride ions.

4.3. Numerical Investigations of Chloride Penetration in a 2Layer System. The chloride ingress and redistribution in a 2-layer system was investigated using the COMSOL multiphysics software [15]. In this case, the chloride penetration was considered to be by diffusion only and described using Fick's law. The mechanisms are modeled in the program by means of differential equations and solved using the finite element method (FEM). The calculations in this section are due to a mean value approach; that is, $\beta=0$.

The results of a FEM simulation are presented in Figure 8. The example shows a structural element made of CEM I concrete which was repaired after 10 years of exposure in a tidal zone (XS3 exposure class). The structural element was repaired by partially removing the $60 \mathrm{~mm}$ thick concrete cover (mean cover depth for XS3 according to the German technical guideline "ZTV-W LB 215" [16]) and replacing it with a CEM III/A concrete. The following two pragmatic criteria were considered when removing the concrete cover in order to avoid the risk of corrosion by the residual chlorides.

(1) The distance between the critical chloride content and the surface of the reinforcement must be at least $10 \mathrm{~mm}$.

(2) The maximum residual chloride content must not exceed $2.0 \mathrm{wt} .-\% / \mathrm{c}$.

In many standards and directives, such as RiLiSIB [17], the mean critical chloride content $\left(C_{\text {crit }}\right)$ is taken to be 0.5 wt.$\% / c$. In order to comply with these criteria, in this theoretical, numerical investigation, the concrete cover was removed to a depth of exactly $27 \mathrm{~mm}$. Thus the thickness of the remaining concrete cover was $33 \mathrm{~mm}$, with a $27 \mathrm{~mm}$ thick layer of repair material being applied.

In Figure 8(a), the chloride profiles 1, 5, 10, and 50 years after repair and external chloride exposure are compared with the residual chloride profile immediately before repair. The figure shows an unmistakable "back-diffusion" of the residual chloride ions into the layer of repair material and redistribution in the layer of the remaining concrete. The

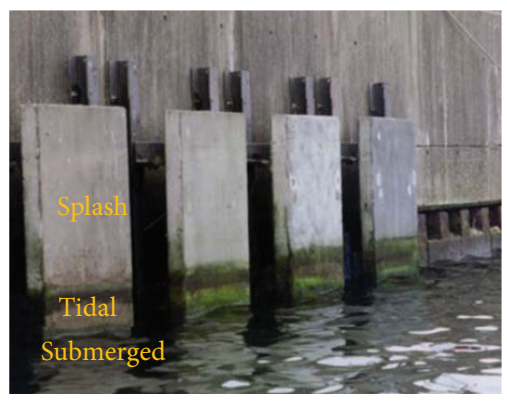

Figure 9: Exposed slabs on the Baltic Sea coast.

critical chloride content is exceeded at the surface of the reinforcement after a period of around 50 years.

Figure 8(b) shows the redistribution of the residual chloride ions without an external supply of chlorides. It can be clearly seen in the figure that the chloride content at the rebar surface (depth of $60 \mathrm{~mm}$ ) remains consistently below $C_{\text {crit }}$ during redistribution of the chloride ions, thus demonstrating compliance with the criteria regarding the depth to which the remaining concrete has to be removed in order to avoid the risk of corrosion in this case.

4.4. Exposure Tests. While laboratory tests form the basis for developing durability models, such models are verified, calibrated, and validated by studying structures and by field tests. Thus the models are checked against the conditions existing in actual practice and modified as required.

In 1991, the Federal Waterways Engineering and Research Institute (BAW) and the Institute of Building Materials Research (ibac) produced large concrete slabs $(2.45 \times 1.40 \times$ $0.12 \mathrm{~m}^{3}$ ) coated with a variety of repair materials as part of a research project to study the durability of repair materials for use in marine environments [18]. The slabs were exposed in four different locations, including marine structures on the North Sea and Baltic Sea coasts. Figure 9 shows the 


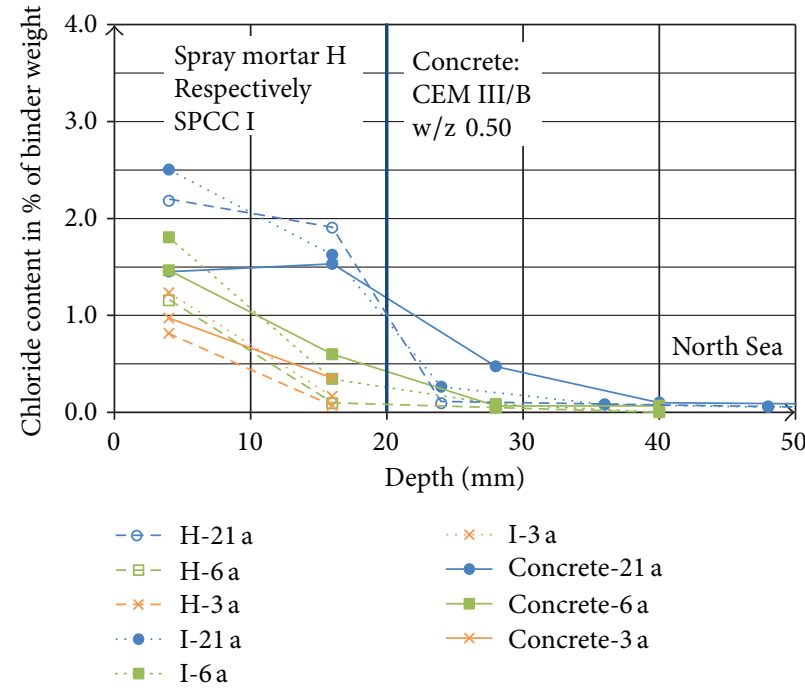

(a)

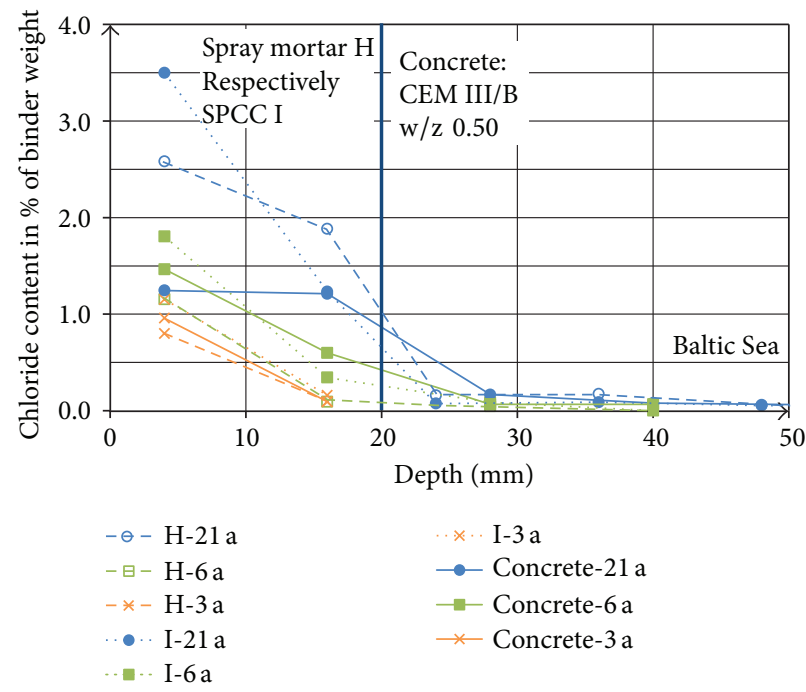

(b)

FigURE 10: Chloride profiles of concrete slabs coated with mortars $H$ and I after 3, 6, and 21 years' exposure on the North Sea (a) and Baltic Sea coast (b).

test location on the Baltic Sea coast. The slabs cover three exposure zones: submerged (XS2), tidal, and splash (XS3) zones. The exposed slabs correspond to Case 2 in Section 3.

The studies focused on investigating all the characteristics of relevance to the durability of the eight selected repair systems, such as frost resistance, resistance to water penetration, and bond strength. Two sprayed mortars (shotcrete) proved to be suitable repair materials. Their resistances to chloride ingress behave in a similar way to those concretes made with CEM III/B; these were the sprayed mortar " $H$ " modified with microsilica and the polymer-modified sprayed mortar (SPCC) "I." Chloride profiles for these materials after 3, 6, and 21 years are available. They were obtained by determining the total chloride content of ground drill cores taken from the slabs. The concrete is a CEM III/B concrete with a water/cement ratio of 0.50 . The concrete layer and the mortar layer are $120 \mathrm{~mm}$ and $20 \mathrm{~mm}$ thick, respectively. Figure 10 shows, by way of an example, the chloride profiles for the concrete slabs coated with the sprayed mortars and those for uncoated slabs in the tidal zone.

It can be clearly seen that after 21 years' exposure the chloride contents at the surface in the case of sprayed mortar are considerably higher than for concrete. However, the initially high values decrease to such an extent over the profile that the chloride contents in the concrete of the coated slabs are either lower or the same as those of the uncoated slabs. It can also be seen that a stagnation of the chloride transport in the outer zone (convection zone) of the slabs without mortar has taken place which does not correspond to a diffusion process. This is presumably due to the removal (washing off/back-diffusion) of the chloride ions in the outer zone. Thus the sprayed mortar and the concrete possess different long-term behaviors due to the chloride ingress which it was not possible to observe in the early investigations after 3 and 6 years' exposure. It is also possible that an interfacial resistance caused by pore blocking leads to the high chloride

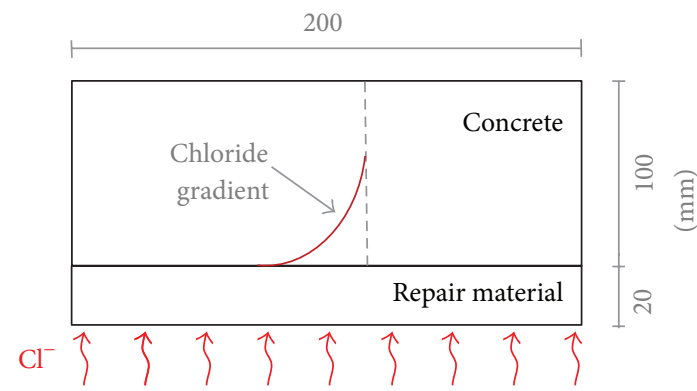

FIGURE 11: Laboratory storage tests with composite specimens (width: $200 \mathrm{~mm}$ )

concentration in the sprayed mortar layer (see Section 3, Case 2). Further investigations into this effect are required.

4.5. Current Laboratory Investigations. Laboratory investigations are currently being conducted to observe and model chloride transport mechanisms in a 2-layer system. Composite specimens comprising a concrete layer with chloride gradients and a layer of repair material, see Figure 11, were prepared for the investigations. The ingress, back-diffusion, and redistribution mechanisms for chloride ions in the layer of repair material and the layer of concrete are being studied in long-term laboratory storage tests. The storage tests with the different types of specimen and the storage conditions are summarized in Table 1 . Three different types of concrete (OPC $\left(320 \mathrm{~kg} / \mathrm{m}^{3}\right)$ with different $w / c$-ratios: 0.55, 0.60, 0.65, aggregate: gravel with grading $\mathrm{AB} 8$ ) and a single repair material (PCC: polymer modified cement concrete, max. grain size $2 \mathrm{~mm}$ ) are being investigated.

The concrete test specimens were first stored in a $3 \% \mathrm{NaCl}$ solution for around 280 days (over 9 months) (one-sided exposure). After the chloride gradients in the test specimens 
TABLE 1: Laboratory storage tests.

\begin{tabular}{lccc}
\hline Test series & Specimen & Storage & Studying mechanism \\
\hline 1 & Composite specimen with chloride gradients in concrete & $\mathrm{Cl}-\mathrm{Cl}$ & $\mathrm{D}, \mathrm{B}, \mathrm{R}$ \\
2 & Composite specimen with chloride gradients in concrete & $\mathrm{Cl}-$ water & $\mathrm{B}, \mathrm{R}$ \\
3 & Composite specimen & $20^{\circ} \mathrm{C} / 65 \% \mathrm{RH}-\mathrm{Cl}$ & $\mathrm{D}$ \\
4 & Concrete specimen with chloride gradients & $\mathrm{Cl}-20^{\circ} \mathrm{C} / 65 \% \mathrm{RH}$ & $\mathrm{R}$ \\
\hline
\end{tabular}

D: diffusion (ingress) of external chloride ions into the repair layer and further into the concrete layer.

B: "back-diffusion" of residual chloride ions from the concrete into the repair layer.

R: redistribution of residual chloride ions in the concrete layer.

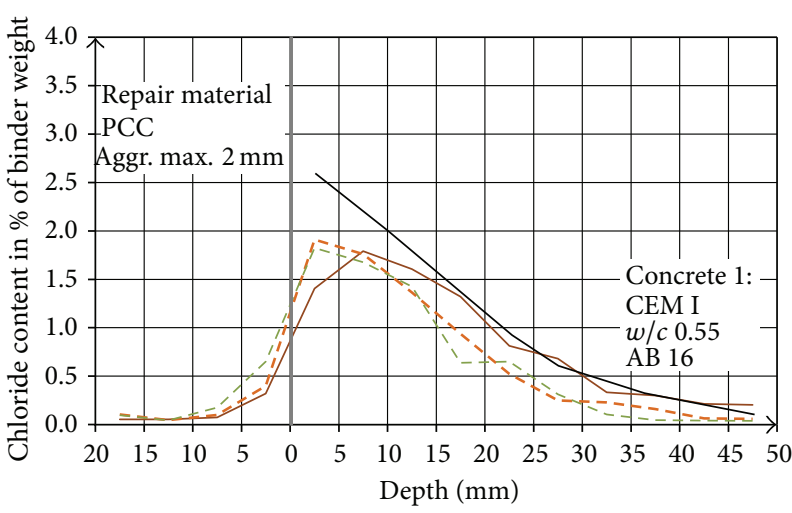

- Concrete $1-280 \mathrm{~d}$ in $\mathrm{Cl}$
- Concrete $1+$ repair-28 d-dry
--- Concrete $1+$ repair-35 d in water
--- Concrete $1+$ repair-91 d in water

(a)
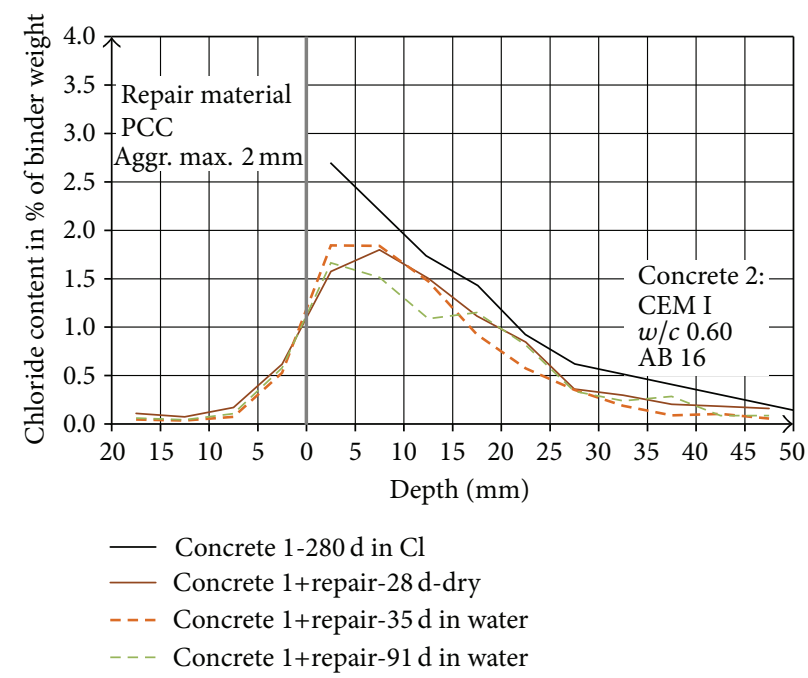

(b)

Figure 12: Chloride profiles of test series 2 (storage Cl-water); (a) concrete 1 with $w / c=0.55$; (b) concrete 2 with $w / c=0.60$.

had been determined, the latter were topped with a repair mortar $(20 \mathrm{~mm})$. The composite specimens were then stored in the laboratory at $20^{\circ} \mathrm{C} / 65 \% \mathrm{RH}$ for 28 days. At this point, the change in the chloride gradient was investigated before the specimens were stored as shown in Table 1. In test series 1 , the composite specimens were stored in a $3 \% \mathrm{NaCl}$ solution in order to investigate each of the processes occurring during chloride transport in a 2-layer system. In test series 2, the composite specimens were stored in water in order to observe the redistribution and back-diffusion through the repair layer. In series 3 , composite specimens without chlorides in the concrete layer were stored in a $3 \% \mathrm{NaCl}$ solution in order to investigate the chloride diffusion without the presence of chloride gradients in the concrete layer. In the last test series 4 , the concrete specimens were sealed with epoxy resin after being stored in the chloride solution for 280 days and subsequently stored in dry conditions in the laboratory at $20^{\circ} \mathrm{C} / 65 \% \mathrm{RH}$ in order to observe the redistribution of the chlorides in them.

The possible transport of the chlorides into the remaining concrete layer or into the new layer after application of the repair layer has already been discussed in Section 4.1. The effects-capillary suction, diffusion, and washing outcan promote transport of the chlorides in either direction.
In order to achieve a better bond between the two layers, the surfaces of the concrete test specimens were first sandblasted immediately prior to application of the mortar layer. Material was removed to a mean depth of around $1 \mathrm{~mm}$. The concrete test specimens were taken out of the $3 \% \mathrm{NaCl}$ solution around one and a half days before application of the repair mortar and stored in dry conditions. The moisture content of the new mortar layer was considerably higher than that of the remaining concrete layer. The distinct moisture gradient initially seems to indicate that the water is being transported from the mortar layer into the concrete layer by capillary suction. This may promote transport of the chlorides from the surface of the test specimen into the inside of the specimen. However, the results of the laboratory tests show that there is a pronounced transport of the chlorides into the new mortar layer (see Figure 12). Further observations are needed to explain this behaviour.

The results of the laboratory tests in series 2 are shown in Figure 12. A pronounced transport of the chlorides into the new mortar layer 28 days after application of the mortar can be observed. The chloride profiles obtained after the test specimens which had been stored in water for 35 and 91 days, respectively, indicate a slight transport of the chlorides from the inside of the test specimens towards the 
surface of the concrete and from there into the new mortar layer.

The binder content of the PPC repair material was estimated at $500 \mathrm{~kg} / \mathrm{m}^{3}$ to enable the chloride content of the binder as a percentage by weight to be determined. In order to establish the chloride profiles, slices were cut with a spacing of $5 \mathrm{~mm}$ from the full depth of two specimens of each concrete and subsequently ground. The other chloride profiles are planned for $180 \mathrm{~d}, 365 \mathrm{~d}, 550 \mathrm{~d}$, and $730 \mathrm{~d}$.

The long-term resistance of repair materials to chloride ingress is the subject of further investigations. As already described in Section 2, the apparent chloride diffusion coefficient, $D_{\text {app,C }}$, decreases over time. This time dependence is modeled using the ageing exponent, $\alpha$, which has a major influence on the service life of structural elements. Little is known about the long-term behavior of repair materials and their composition is also unknown. However, comparative tests with concrete with known ageing exponents are being conducted in an attempt to estimate the ageing exponents of the repair materials in spite of this.

\section{Summary}

The methodology of determining the residual service life of concrete structural elements before and after a repair measure based on an existing concept for calculating the service life of new concrete marine structures has been described in this paper. The process by which diffusion of chloride ions takes place in a 2-layer system and the mathematical modelling of that process have been discussed. An approximate calculation of the residual service life of repaired structural elements has been presented. The redistribution of the residual chloride ions in the remaining layer of concrete and in the repair layer has been demonstrated by performing sample FEM numerical calculations. The effects of the content and gradient of the residual chloride ions on the residual service life of structural elements have been illustrated by examples.

The distribution of residual chlorides after application of a repair material is being studied in laboratory investigations. Immediately after application of a repair material to the concrete member, the residual chlorides migrate from the concrete layer to the new layer. Laboratory investigations are needed to study the mechanisms by which chloride ions are transported in a 2-layer system and field investigations are essential to enable the results of the laboratory investigations to be assessed for their relevance in practical applications.

\section{Conflict of Interests}

The authors declare that there is no conflict of interests regarding the publication of this paper.

\section{References}

[1] fib Bulletin 34, "Model Code for Service Life Design," Model Code prepared by fib Task Group 5.6, 2006.

[2] NT Build 492, "Concrete, Mortar and Cement-Based Repair Materials-Chloride Migration Coefficient from Non-SteadyState Migration Experiments," 11.99.
[3] BAW Code of Practice, "Resistance of Concrete to Chloride Penetration (MCL)," 2012.

[4] C. Gehlen, "Probabilistische Lebensdauerbemessung von Stahlbetonbauwerken-Zuver-lässigkeitsbetrachtungen zur wirksamen Vermeidung von Bewehrungskorrosion," Schriftenreihe des Deutschen Ausschusses für Stahlbeton, Heft 510. Beuth, Berlin, Germany, 2000.

[5] EN 1990-Eurocode 0, "Bases of structural design," CEN, Brussels, Belgium, 2002.

[6] ISO 2394:1998, "General principles on reliability of structures".

[7] "Positionspapier des DAfStb zur Umsetzung des Konzepts von leistungsbezogenen Entwurfsverfahren unter Berücksichtigung von DIN EN 206-1, Anhang J," Beton- und Stahlbetonbau 103, 2008.

[8] fib Bulletin 59, "Condition Control and Assessment of Reinforced Concrete Structures," State-of-art report prepared by fib Task Group 5.8, 2011.

[9] D. Straub, "Reliability updating with inspection and monitoring data," in Proceedings of the 11th International Conference on Applications of Statistics and Probability in Civil Engineering (ICASP '11), Deteriorating Reinforced Concrete Slabs, ETH Zurich, Switzerland, 2011.

[10] H. S. Carslaw and J. C. Jaeger, Conduction of Heat in Solids, Clarendon Press, Oxford, UK, 1959.

[11] J. Crank, The Mathematics of Diffusion, Clarendon, Oxford, UK, 2nd edition, 1975.

[12] H. Martin, "Zeitlicher Verlauf der Chloridionenwanderung in Beton, der einem PVC-Brand ausgesetzt war," Betonwerk + Fertigteiltechnik, 1975.

[13] C. Gehlen and C. Fischer, "Überarbeitung des BAW-Merkblatts Chlorideindringwiderstand von Beton," Institut für Werkstoffe im Bauwesen der Universität Stuttgart, Forschungsbericht A07/ $1-1,2007$.

[14] STRUREL-A structural reliability analysis program system by RCP GmbH (Reliability Consulting Programs), http://www .strurel.de/.

[15] COMSOL Multiphysics-Multiphysics Modeling, Finite Element Analysis, and Engineering Simulation Software, http://www .comsol.com.

[16] ZTV-W LB 215, "Zusätzliche Technische Vertragsbedingungen-Wasserbau (ZTV-W) für Wasser-bauwerke aus Beton und Stahlbeton (Leistungsbereich 215)," Ausgabe $2004+1$. Änderung 2008.

[17] RiLi SIB, "Richtlinie für Schutz und Instandsetzung von Betonbauteilen," Teil 1: Allgemeine Regelungen und Planungsgrundsätze. Deutscher Ausschuss für Stahlbeton (DAfStb), 2001.

[18] G. Rössler, A. Westendarp, C. Dauberschmidt et al., "Instandsetzung von Meerwasserbauten," ibac-Forschungsbericht F647, 2009. 

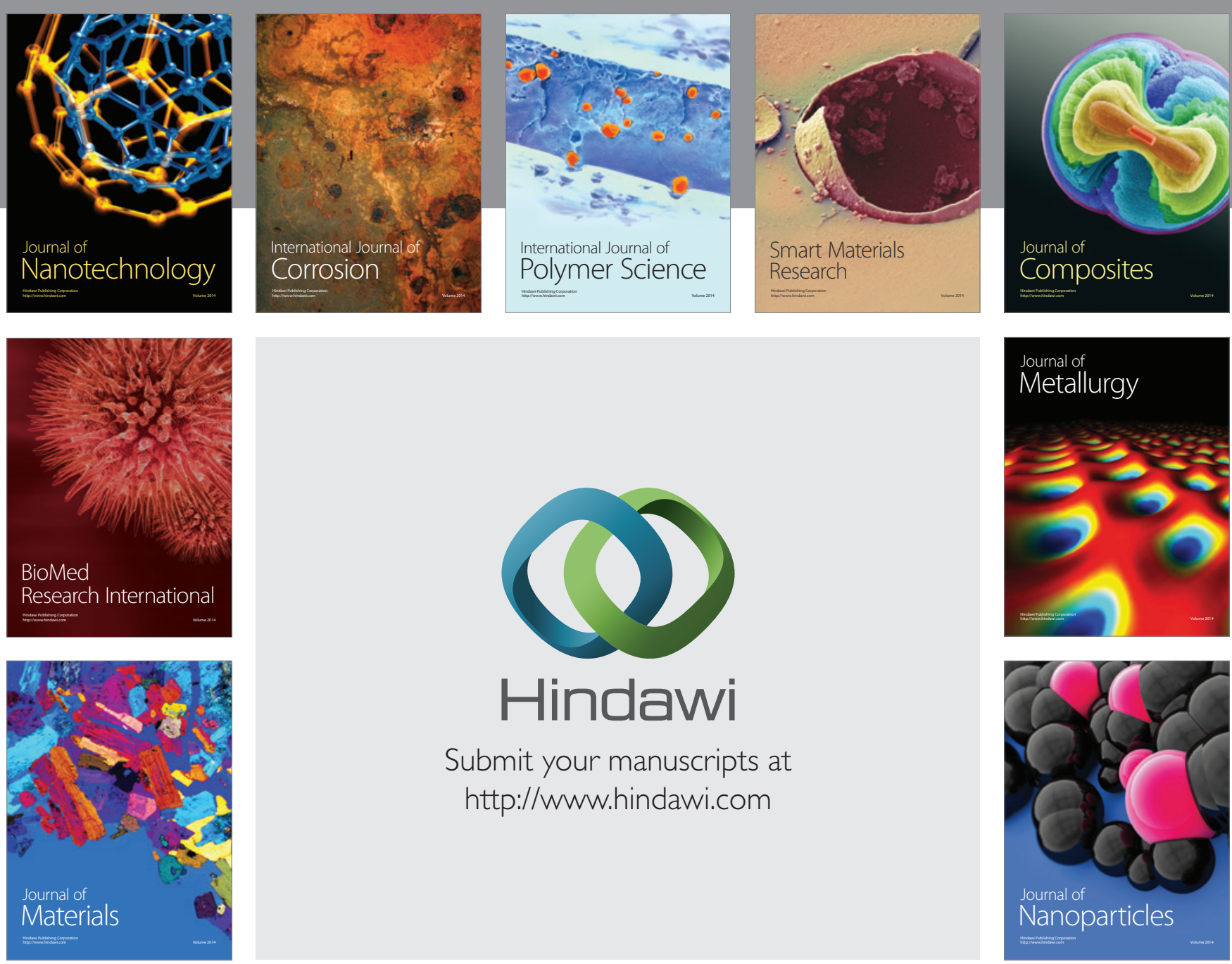

Submit your manuscripts at http://www.hindawi.com
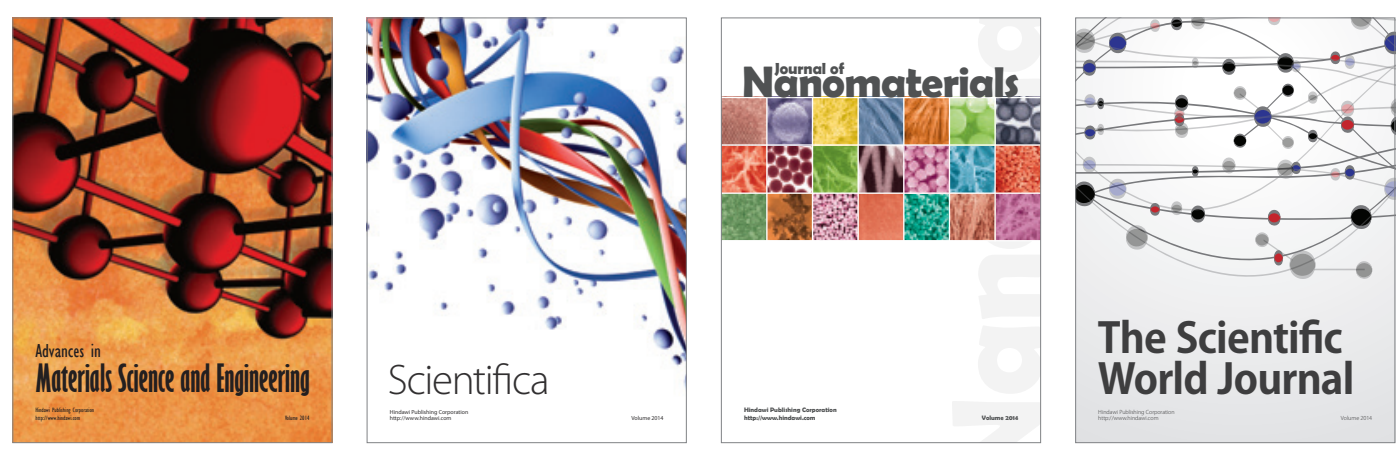

\section{The Scientific World Journal}
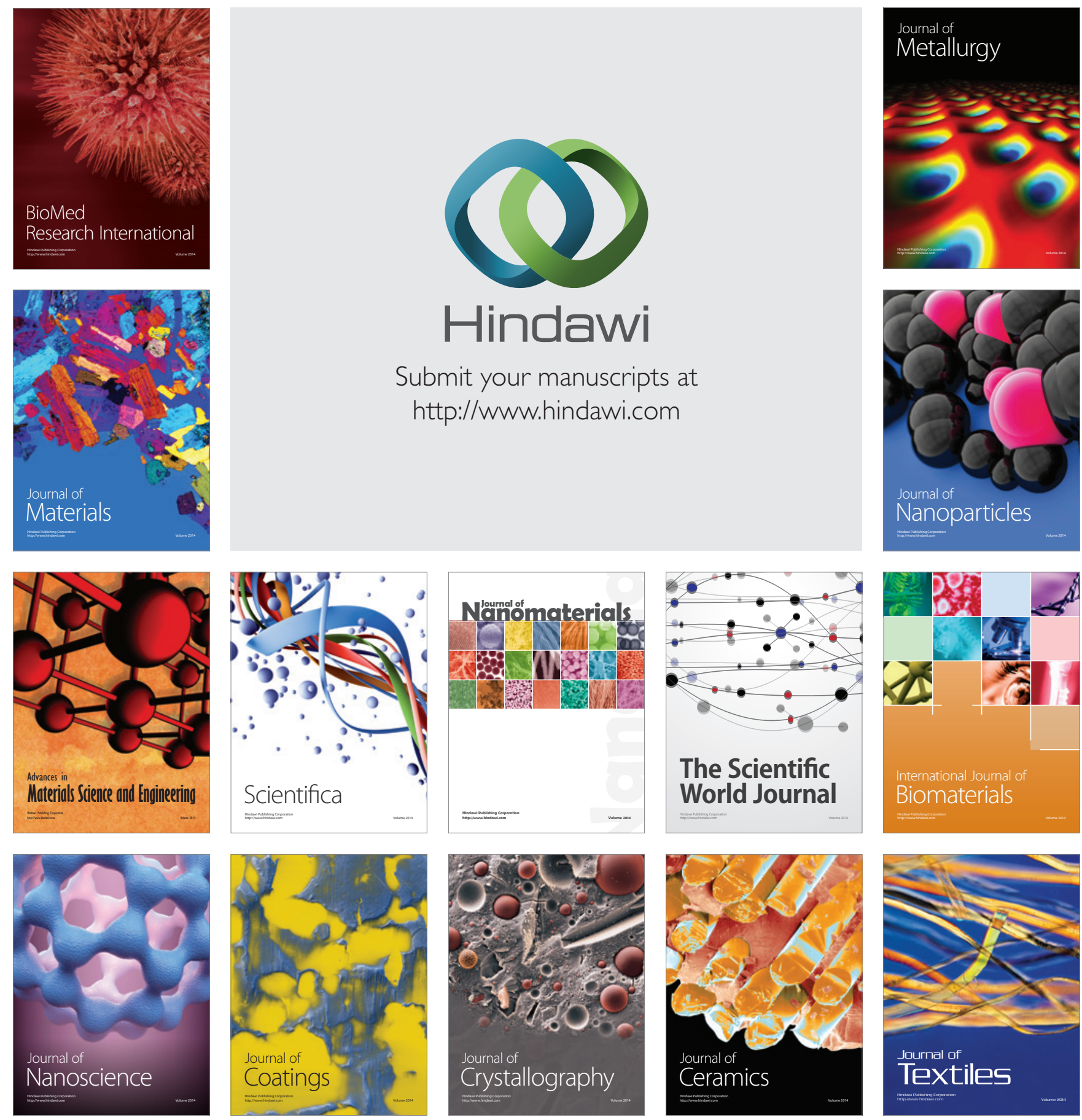